\title{
Hispanic Youth/Young Adults with Disabilities: Parents' Visions for the Future
}

\author{
Martha Blue-Banning and Ann P. Turnbull \\ The University of Kansas \\ Lourdes Pereira \\ The University of Georgia
}

\begin{abstract}
The rapid increase of culturally and linguistically diverse populations in the United States has important implications for service delivery. Addressing the needs of individuals transitioning from adolescence to adulthood and their families requires that outcomes of service recognize the cultural differences of people with disabilities. The Hispanic population is one of the fastest growing of the culturally and linguistically diverse populations in the United States. To provide effective support services, a clearer understanding is needed of the perspectives of Hispanic parents of youth/young adults with disabilities concerning their hopes and expectations for their child's future. To address this issue, focus group interviews were conducted with 38 Hispanic parents of youth/young adults with developmental disabilities. The findings suggest that Hispanic parents have a diversity of hopes and expectations concerning future living, employment, and free-time options, for their children with disabilities. Key recommendations focus on the implications for education and human service systems as well as directions, for future research.
\end{abstract}

DESCRIPTORS: Hispanic, transition, visions, qualitative

Research on the post-school outcomes of students with disabilities making the transition from high school to adulthood indicates that most students with disabilities do not fare well after leaving school (Ysseldyke et al., 2000), often graduating to segregated, dependent, nonproductive lives (Blackorby \& Wagner, 1996; National Center for Educational Statistics, 2000; National Council on Disability, 2001). Over the past two decades, discouraging post-school outcomes for graduates with disabilities have changed perspectives on the transition from school to adult services for individuals with disabilities (e.g., Blackorby \& Wagner, 1996; Chadsey-Rusch \&

Address all correspondence and requests for reprints to Martha Blue-Banning or Ann Turnbull, Beach Center on Disabilities, Haworth Hall, University of Kansas, Lawrence, KS 66045-7534.
Heal, 1995; Johnson \& Rusch, 1993) and have prompted a renewed focus on the significance of this transition (Browning et al., 1995; Ross, 1996; NCES, 2000; NCD, 2001).

Initial federal initiatives that focused on transition services for students with disabilities identified employment as the defining characteristic or desired outcome of adult life (DeStefano \& Wermuth, 1992). Transition has since been broadened to include community living, personal choice, and autonomy in adult life (GallivanFenlon, 1994; Moon \& Inge, 2000). Evident throughout the transition literature are the assumptions that desired post-school outcomes for students with disabilities include indicators of independence (e.g., employment), post-secondary education, and residential options away from the parents' home (e.g., Moon \& Inge, 2000; Shafer \& Quiroga, 1993).

This view is also reflected in federal legislation. At though the Individuals with Disabilities Fducation Act (IDEA) mandates that the long-range plan, coordinated activities, and annual individualized education program (IEP) goals and objectives during the transition process must be developed from post-school outcomes, based on the individual student's needs and the student's preferences and interests, the language of IDEA is reflective of presumed societal norms. Independence is a foundational concept of IDEA, which identifies postschool outcomes such as post-secondary education, integrated employment (including supported employment), and independent living [20 U.S.C. § 1401 (30)].

The post-school outcomes literature also clearly suggests that specific outcomes are traditionally considered desirable by U.S. society for youth leaving school (Car \& Ratcliff, 1994). In addition, such service systems as the educational system, typically use professionals whose values reflect those of the dominant U.S. culture, including self-reliance, independence, and achievement (Banks, 1994; Crago \& Eriks -Brophy, 1993). Hence, educators and other professionals' cultural assumptions may vary significantly from the individuals they support 
who have culturally and linguistically diverse backgrounds (Sitlington et al., 2000). Although the need for culturally referenced and culturally appropriate goals and services is becoming more widely recognized, a prevalent belief is that the cultural reference point for goals and services should be provided by mainstream values (Harry et al., 1999).

Reflective of rapidly changing U.S. demographics, with culturally and linguistically diverse groups comprising an increasingly larger segment of the population, the field of special education is faced with a tre mendous challenge as the United States' student population becomes more diverse (Harry, 1992; Ysseldyke et al., 2000). For example, the United States' Hispanic population increased $57.9 \%$ between 1990 and 2000, as compared with the total U.S. population, which increased just $13.2 \%$ (Guzman, 2001). The Hispanic population is one of the fastest growing culturally and linguistically diverse groups in the U.S. (Garcia-Preto, 1996) and is projected to contribute 44\% of the nations' population growth between the years 2000 and 2020 (U.S. Census Bureau, 1996). These rapidly changing demographics mean that education professionals will be working with increasingly culturally and linguistically diverse students and families, whose values and beliefs may differ significantly from those of the dominant U.S. culture (Kalyanpur \& Harry, 1999; Lynch \& Hanson, 1998).

Schalock (2000) suggests that the concept of quality of life has significantly influenced education, health care, and mental health service systems and should be the basis for public policy and service delivery principles. As the United States becomes increasingly culturally heterogeneous, Edgerton (1990) warns against determining a single set of standards for quality of life acceptable for all U.S. citizens, because quality of life is individually interpreted within the context of the individual's culture. Schalock (1997) contends that culture and ethnicity determine quality of life. He suggests that there may be discrepancies in concepts of happiness, satisfaction, and well-being across cultures that lead to differing conceptions of the meaning of quality of life and its applications

In the disability field, there is an increasing awareness of the need to begin with the perspective of each individual rather than defining one style of life as standard for all people. In program planning, addressing the needs of culturally and linguistically diverse students and their families requires that outcomes-based service delivery recognize and respect the cultural differences of people with disabilities (Dennis et al., 1993; Kalyanpur \& Harry, 1999). This is particularly true for special education and adult service professionals as they support individuals with disabilities who exit from school to adult life (Navarrete \& White, 1994). For example, emphasis placed on independent living after high school by individuals with disabilities and their families will vary by ethnic group and culture (Wehman et al., 2000).
The importance of family involvement in educational planning has long been recognized and is evident in public policy, research and federal legislation (Cimera \& Rusch, 2000). Indeed, parent participation is one of the six fundamental principles of IDEA (Turnbull \& Turnbull, 2000). Families play a major role in the transition of individuals with disabilities to adulthood and have been identified as perhaps the single most important element in the total transition continuum (Everson \& Moon, 1987; McNair \& Rusch, 1991). Many individuals with disabilities continue to live with or to receive intense support from their parents hroughout their lives (Freedman et al., 1997; Heller et al., 1997; Lakin, 1996). Given this fact, it is noteworthy that the majority of disability research in education is comprised of quantitative studies that focus on student issues. In comparison, the concerns, needs, and expectations of parents of youth with disabilities have seldom been the focus of research (Hanley-Maxwell et al., 1995; Johnson \& Rusch, 1993). Moreover, few of the studies that have investigated these factors related to parents of youth and young adults include the perspectives of Hispanic parents.

The current study, which was a component of a larger qualitative study, was designed to examine the perspectives of Hispanic parents of youth and young adults with disabilities regarding heir hopes and expectations for their child's future.

\section{Method}

Focus group interviews were used for data collection for two reasons. First, focus groups have been identified as particularly useful when working with groups of people who have a history of limited power and influence, such as individuals from culturally and linguistically diverse backgrounds (Morgan \& Krueger, 1993). Second, a wider range of information and insight is produced from the combined effort of the group than would be accrued by privately obtained individual participant responses (Stewart \& Shamdasani, 1990).

\section{Participants}

Focus group participants were Hispanic parents of youth and young adults with developmental disabilities (e.g., cerebral palsy, autism, cognitive disabilities). A total of 38 participants took part in focus groups across four states: (a) Texas, (b) California, (c) Kansas, and (d) Connecticut. Focus groups were conducted in four different geographic locations for two reasons. First, these research sites were chosen to ensure representation of the two dominant U.S. Hispanic subgroups, Mexican and Puerto Rican, which currently represent $75 \%$ of the U.S. Hispanic population (Massey et al., 1995; Ortiz, 1995). Second, focus groups were conducted at four different geographic sites to avoid 
construing one specific community as "representative" of all Hispanics. Krueger (1994) emphasizes exercising caution when focus group participants represent diverse categories of people such as culturally and linguistically diverse groups, which comprise many subgroups. Although many Hispanic families are linked by cultural values that transcend subgroup differences, it is important to recognize that cultural attributes are tendencies rather than absolutes and are not rigidly fixed to any one individual or family (Anderson, 1989). In addition, Hispanics are a heterogeneous population, living in all areas of the United States and representing different levels of acculturation.

Purposive sampling was used to identify participants Marin and Marin (1991) identify ancestry as the best way of operationalizing Hispanic ethnicity. Therefore, for participation in this study, parents who identified their country of ancestry as Mexico, Puerto Rico, Cuba, Central America, or South America met the criterion of Hispanic ethnicity. The majority of participants were mothers (34) and listed their country of origin as Mexico (18) or Puerto Rico (15). Most also were first generation Americans (27) and had incomes under $\$ 15,000$ (22). Table 1 highlights the demographics of the 38 participants.

Working through professional and personal networks with Hispanic leaders and leaders of family support groups or organizations and agencies serving families of individuals with disabilities in each of the four research communities, a parent of a child with a disability who was considered a leader in the Hispanic community was identified to serve as a research site coordinator.

Table 1

Participant Demographic Information

\begin{tabular}{|c|c|c|c|c|c|c|c|c|c|c|}
\hline \# & Relationship & $\begin{array}{l}\text { Child's } \\
\text { gender }\end{array}$ & $\begin{array}{l}\text { Child's } \\
\text { age }\end{array}$ & $\begin{array}{l}\text { Child's } \\
\text { disability }\end{array}$ & Severity & Income & Employment & $\begin{array}{c}\text { Country of } \\
\text { origin }\end{array}$ & Generation & $\begin{array}{l}\text { Primary } \\
\text { language }\end{array}$ \\
\hline 1 & Mother & $\mathrm{F}$ & 8 & Autism & Mild & $-15,000$ & Unemployed & Puerto Rico & First & Spanish \\
\hline 2 & Mother & $\mathrm{F}$ & 9 & $\mathrm{OHI}$ & Profound & $-15,000$ & Unemployed & Puerto Rico & First & Spanish \\
\hline 3 & Father & $\mathrm{F}$ & 9 & $\mathrm{OHI}$ & Profound & $-15,000$ & Unemployed & Puerto Rico & First & Spanish \\
\hline 4 & Mother & $\mathrm{F}$ & 10 & $\mathrm{LD} / \mathrm{OHI}$ & Mild & $35,000-50,000$ & Part-time & Mexico & Third & English \\
\hline 5 & Mother & $\mathrm{F}$ & 12 & $\mathrm{ED} / \mathrm{LD}$ & Mild & $-15,000$ & Unemployed & Puerto Rico & First & Spanish \\
\hline 6 & Mother & $\mathrm{F}$ & 12 & MR/01 & Severe & $-15,000$ & Unemployed & Puerto Rico & First & Spanish \\
\hline 7 & Father & $\mathrm{F}$ & 13 & Autism/MR & Severe & $35,000-50,000$ & Full-time & Mexico & Third & Both \\
\hline 8 & Mother & $\mathrm{F}$ & 13 & MR/OI & Moderate & $35,000-50,000$ & Unemployed & Puerto Rico & First & English \\
\hline 9 & Mother & $\mathrm{F}$ & 14 & LD & Mild & $25,000-35,000$ & Full-time & Mexico & Third & Both \\
\hline 10 & Mother & $\mathrm{F}$ & 14 & MR & Moderate & $-15,000$ & Unemployed & Mexico & First & Spanish \\
\hline 11 & Mother & $\mathrm{F}$ & 15 & MR & Moderate & $-15,000$ & Unemployed & Mexico & Missing & Missing \\
\hline 12 & Mother & $\mathrm{F}$ & 19 & LD & Moderate & $35,000-50,000$ & Full-time & Mexico & First & English \\
\hline 13 & Mother & $\mathrm{F}$ & 20 & $\mathrm{MR} / \mathrm{OI}$ & Moderate & $-15,000$ & Part-time & Mexico & First & Spanish \\
\hline 14 & Father & $\mathrm{F}$ & 21 & MR & Severe & $-15,000$ & Unemployed & Mexico & Second & Spanish \\
\hline 15 & Mother & $\mathrm{F}$ & 21 & MR & Severe & $-15,000$ & Unemployed & Mexico & First & Spanish \\
\hline 16 & Mother & $\mathrm{F}$ & 8 & MR & Profound & $-15,000$ & Unemployed & Puerto Rico & Missing & Spanish \\
\hline 17 & Mother & M & 11 & Autism & Moderate & $15,000-25,000$ & Unemployed & Puerto Rico & First & Both \\
\hline 18 & Mother & M & 11 & MR & Severe & $-15,000$ & Full-time & Mexico & First & Spanish \\
\hline 19 & Mother & M & 11 & $\mathrm{MR} / \mathrm{OHI}$ & Severe & $-15,000$ & Unemployed & Puerto Rico & First & Spanish \\
\hline 20 & Mother & M & 12 & MR/ED & Severe & $50,000-75,000$ & Unemployed & $\begin{array}{l}\text { Mexico/Puerto } \\
\text { Rico }\end{array}$ & Third & English \\
\hline 21 & Mother & M & 13 & MR & Mild & $25,000-35,000$ & Part-time & Mexico & Second & Both \\
\hline 22 & Mother & M & 13 & MR & Moderate & $25,000-35,000$ & Unemployed & Mexico & Third & Both \\
\hline 23 & Mother & M & 14 & MR & Severe & $-15,000$ & Part-time & Puerto Rico & First & Both \\
\hline 24 & Mother & M & 14 & MR & Severe & $-15,000$ & Unemployed & Mexico & First & Spanish \\
\hline 25 & Mother & M & 15 & ED/LD & Moderate & $35,000-50,000$ & Full-time & Mexico & First & Spanish \\
\hline 26 & Mother & M & 16 & $\mathrm{ED} / \mathrm{LD}$ & Moderate & $-15,000$ & Unemployed & $\begin{array}{l}\text { Dominican } \\
\text { Republic }\end{array}$ & Second & Spanish \\
\hline 27 & Mother & M & 16 & ED/LD & Moderate & $-15,000$ & Unemployed & Puerto Rico & First & Spanish \\
\hline 28 & Mother & M & 17 & LD & Moderate & $15,000-25,000$ & Full-time & Nicaragua & First & Spanish \\
\hline 29 & Father & M & 17 & LD & Moderate & $15,000-25,000$ & Full-time & Nicaragua & First & Spanish \\
\hline 30 & Mother & M & 17 & LD/OI & Moderate & $15,000-25,000$ & Unemployed & Mexico & First & Spanish \\
\hline 31 & Mother & M & 17 & MR & Mild & $25,000-35,000$ & Full-time & So. America & First & Spanish \\
\hline 32 & Mother & M & 18 & ED/LD & Severe & $15,000-25,000$ & Full-time & Mexico & First & Spanish \\
\hline 33 & Mother & M & 18 & $\mathrm{MR} / \mathrm{OI}$ & Severe & $-15,000$ & Unemployed & Puerto Rico & First & Spanish \\
\hline 34 & Mother & M & 20 & OI & Severe & $-15,000$ & Unemployed & Mexico & First & Spanish \\
\hline 35 & Mother & M & 20 & OI & Mild & $-15,000$ & Unemployed & Puerto Rico & First & Spanish \\
\hline 36 & Mother & M & 21 & $\mathrm{ED} / \mathrm{OI}$ & Mild & $-15,000$ & Unemployed & Mexico & Missing & Missing \\
\hline 37 & Mother & M & 21 & $\mathrm{MR} / \mathrm{OI}$ & Severe & $15,000-25,000$ & Part-time & Puerto Rico & First & Spanish \\
\hline 38 & Mother & M & 22 & MR & Profound & $-1.5,000$ & Full-time & Puerto Rico & First & Both \\
\hline
\end{tabular}

Note: $\mathrm{OHI}=$ other health impaired $\mathrm{LD}=$ learning disability; $\mathrm{MR}=$ mental retardation; $\mathrm{OI}=$ orthopaedic impairment; $\mathrm{ED}=$ emotional disability 
Magaña (2000) identified the importance of involving community leaders in helping researchers establish trust within the community as well as for sample recruitment. The site coordinator role was multifaceted and varied, depending on each community's individual and contextual factors.

Once the site coordinators were in place, members of the research team and coordinators worked collaboratively to identify participants for the focus groups. Site coordinators contacted potential participants by telephone and explained the purpose of the study. The majority of parent participants had some degree of involvement with or assistance from the family support group or agency with which the site coordinator was associated. Coordinators described what participating in the study involved; they provided the date, time, and location of the focus group; and they extended an invitation to participate. In addition to securing focus group participants, the coordinators also provided critical information and feedback to the researchers, which enabled them to be sensitive and responsive to the individual communities. For example, knowing the unique situations within their communities, coordinators identified a nonthreatening location and convenient time for focus groups to meet.

The site coordinators' role in the actual focus groups also varied by community. The Texas and Kansas site coordinators, parents of children with disabilities, were focus group participants. The Connecticut site coordinator, an experienced focus group facilitator, assisted the moderator in the focus group for Spanish-speaking participants. The California coordinator had no direct participation in the focus groups.

Incentives are particularly important in focus group research, because participant investment in terms of time and effort is greater than for most other data collection methods (Krueger, 1994). Incentives at all research sites included providing a meal before the star of the focus groups. provision of childcare during the focus groups, a T-shirt, and a monetary incentive. In Texas and California, participants received a $\$ 15$ check for focus group attendance. Based on recommendations by the Kansas and Connecticut coordinators, participants in these states received a coupon from a community grocery store.

\section{Data Collection}

A total of seven focus groups were conducted, each lasting approximately two hours. One focus group was conducted in both English and Spanish, three in English only, and three in Spanish only. Initially, one focus group was projected at each research site with translation provided to Spanish-speaking participants. Mixing language preference, however, proved unwise, because the required translation inhibited the free flow of discussion. As a result, focus groups were divided according to the primary language of the participants.

A Hispanic member of the research team, fluent in Spanish, moderated the Spanish-speaking focus groups.

A member of the research team facilitated each focus group. The facilitator's role was to create a comfortable environment that would allow group members to share their perceptions and perspectives. During the focus group, participants were seated so they could see each other. They were encouraged to stretch or go to the restroom when needed. Small talk among participants before the group dialogue is essential to creating a friendly, warm, and comfortable environment (Krueger, 1994). Marin and Marin (1991) identified the opportunity for small talk, la plática, before an interview as particularly important for promoting Hispanic participant satisfaction and cooperation. For this reason. Magana (2000) emphasized the need to factor in extra time when planning interviews with Hispanic participants. At each research site, therefore, opportunities for participants to get to know each other were provided during lunch before the focus groups and during the first 5 to 10 min of the focus group.

An interview guide provided direction for group dis cussion. The interview guide reduced language variance that could alter intent, given that four different facilitators were used to conduct the investigation (Miles \& Huberman, 1994). However, facilitators were flexible and were prepared to adapt or change questions so that participants could shape the direction of the discourse. Probes were used to expand on an issue being discussed or to clarify a respondent's meaning. Also, at the end of the discussion, participants had the opportunity to summarize perspectives in response to such questions as, "After thinking about the issues we talked about today, which one is of greatest concern to you?" (Krueger, 1993).

\section{Data Analysis}

There is no one "right way" to analyze qualitative data (Tesch, 1990); however, the process must be systematic, and follow an established, sequential, and verifiable process (Krueger, 1993). The following section describes the three phases of the process used in this study: (a) recording and managing raw data, (h) data reduction, and (c) interpretation.

In terms of data management, all focus groups were audiotaped and professionally transcribed verbatim. A member of the research team checked the transcripts against the audiotapes to ensure accuracy of the transcription. The researcher who facilitated the Spanish-speaking focus groups also transcribed and translated the audiotapes from these groups. After the transcripts were completed, they were imported into The Ethnograph, a qualitative analysis software program designed $\mathbf{b}$ organize and retrieve data (Knodel, 1993). The Ethnograph facilitated the mechanical aspects of physically organizing the data.

Phase 2, data reduction, was a continuous process 
throughout data collection and analysis. During this phase, research team members sorted the data that were important and salient to the questions under investigation from those that were unimportant. The data were then organized and categorized in a search for emerging patterns, themes, and relationships, as guided by the res earch questions (Creswell, 1994).

Four researchers independently read and reread the transcripts to identify segments that were salient to the research questions. The research team discussed individual findings and developed a list of categories that were internally consistent but discrete from one another (Marshall \& Rossman, 1995). Using this list of categories, the research questions, interview questions, and concepts/categories from other researchers or re lated studies (Tesch, 1990), the research team developed a preliminary operative coding framework. Two researchers then reread the transcripts and applied the coding framework, examining it for "fit" (Miles \& Huberman, 1994). A peer debriefing was subsequently held between members of the research team and a colleague who was knowledgeable about the research topic but was an outsider to the research project (Brotherson \& Spillers, 1989; Guba \& Lincoln, 1989; Miles \& Huberman, 1994). The objective was to detemine if the codes identified were accurate reflections of transcript data.

Once relevant information units had been identified and categorized in all transcripts, the categories were reviewed for overlap and completeness. Categories with similar properties were collapsed into one broader category (Vaughn et al., 1996).

A numerical description of the data was obtained through content analysis (Morgan, 1993), resulting in 1,228 coded segments divided among 44 coded categories. This content analysis enabled researchers to evaluate the validity of a category or theme by: (a) the frequency with which it occurred, and (b) its consistency across focus groups (Miles \& Huberman, 1994).

In the final phase of data reduction, two researchers, using the established code list, independently coded the text of a clean copy of each transcript. The coded transcripts from both researchers were then entered into The Ethnograph, which generated output files that contained sorted, crossreferenced, and coded segments. Each researcher reviewed a complete set of output files and determined if he or she agreed that the segment of text fit the coded category. They subsequently discussed their analyses, comparing their interpretations of the coded materials. When disagreement occurred, the researchers discussed the text and code/category in question until consensus was reached (Hanley-Maxwell et al., 1995).

Check-coding was conducted to facilitate clarification of category definition and to establish intra- and intercoder reliability (Miles \& Huberman, 1994). Intercoder reliability was established by dividing the number of agreements by the sum of agreements plus the number of disagreements (Miles \& Huberman, 1994). The average intercoder agreement score across all categories was $90 \%$ (range from $71-100 \%$ ). A check of code-recoder agreement for each researcher was conducted by comparing output files to their individual coded transcripts. The average intracoder agreement was $95 \%$ and $89 \%$, respectively. This evaluation of intracoder reliability allowed researchers to check for internal consistency.

Finally, in the third phase, after sorting and organizing the data, researchers meaningfully reconstructed the data. Through interpreting patterns and themes, the essential meaning was drawn from focus group participants' words. Data displays, including matrix and network formats, were used to reveal connections and relationships among themes.

\section{Verification}

Numerous strategies were implemented throughout this study to verify trustworthiness, including: (a) multiple informants, (b) member checks at the end of each focus group, (c) verbatim transcripts, (d) multiple researchers and analysts, (e) comparable data collection protocols, (f) peer debriefs, and (g) coding checks. Two additional verification strategies were used at the end of this project: (a) comprehensive member checks, and (b) a confirmatory inquiry.

\section{Comprehensive Member Check}

A comprehensive member check was conducted to evaluate the interpretative fairness and validity of the analysis from the perspectives of the original participants (Guba \& Lincoln, 1989; Patton, 1990; Seidman, 1991). Two family member participants from each research site agreed to participate in the review of the research findings. Each reviewer received a packet containing a cover letter, summary report, and a one-page response form. The cover letter included a brief reminder of the intent of the study and an explanation of the summary review they had agreed to complete. Reviewers were asked: (a) if the findings were a reasonable interpretation of the focus group discussion, (b) if important points were left out, and (c) if they had concluding comments or suggestions. Their feedback was provided in oral or written format, according to each reviewer's personal preference. Reviewers' responses were confirmatory and increased researchers' confidence that the data analysis represented stakeholder reality.

\section{Confirmatory Inquiry}

A confirmatory inquiry was conducted to confirm the soundness of the research methods. The purpose of the inquiry was to substantiate that: (a) conclusions made by the research team were consistent, and (b) interpretation of the data was reasonable. The external researcher who conducted the confirmatory inquiry was experienced in qualitative research, not affiliated with the 
current research project, had substantive knowledge of the topic of this study, and was an approximate peer of the primary researcher, to ensure relative equity in their relationship (Guba \& Lincoln, 1989). During the confirmatory inquiry, data were tracked from the final report back to the original transcript. The intent was to ensure congruity between the context quoted material and interpretation. In addition, themes and supporting quoted material presented in the results section were compared with all coded segments for each theme. The purpose was to ensure that the coded segments selected to illustrate each theme were representative of the total body of coded segments for each theme. This process helped to confirm that the findings, summary, and major features of the research were accurately "borne out" by the raw data (Krueger, 1993).

\section{Limitations of the Study}

The purpose of this study was to increase understanding of Hispanic parents' hopes and expectations of the future for their children with disabilities. The intent was to give "voice" to their experiences and to provide a context for understanding, rather than to infer or generalize to a larger population. With this in mind, there are several factors that may limit the results of this study.

First, researchers worked with family support groups and organizations serving Hispanic families of individuals with disabilities in each research community to identify potential participants. The parents who participated in this study were members of and/or had received services (e.g., attended workshops) from these organizations. The knowledge and involvement of these parent participants may not, therefore, be representative of typical parents in their Hispanic communities. The influence of these Hispanic organizations may be reflected in the responses of many participants whose cultural values seem to resemble the goals of the mainstream culture. The insights of parents who are not affiliated with or supported by such groups may provide key perspectives that are not represented by the participants in the current study.

Second, the very fact that these participants agreed to participate in the study implies a possible effect on the findings. The length of time required to attend the workshop and subsequent focus group attests to their level of interest and commitment to this topic. Participants, therefore, may not have been typical representatives of their specific stakeholder group.

Third, it is important to note that these findings are not representative of all Hispanic families. The four geographic locations of the research sites were specifically selected to ensure representation of the two dominant Hispanic subgroups in this country, Mexican and Puerto Rican. Hispanics, however, are a heterogeneous population, living in all areas of the United States and representing different levels of acculturation. Culture is not rigid, rather it is changing and diverse. Szapocznik and Kurtines (1993) emphasize the fact that individuals experiencing varying degrees of exposure to multiple cultures will vary in adherence to the values and behaviors of those cultures. Caution, therefore, must be taken against making broad generalizations or oversimplifying the results of this study.

Fourth, each focus group was conducted only once, providing a single snapshot in time. Participant experiences were not captured across time to determine if their perspectives had changed.

\section{Results}

When parents were asked to describe the "very best life" for their children, they had little difficulty articulating their expectations and hopes for the future. Many envisioned a future that would be consistent with the preferences of their sons or daughters and characterized by their participation in the community.

I want my daughter to be successful.... I think for her, success will be living in the community.... to me success is more of a choice and that choice is going to be more of her choice, because I believe that even though now it is very difficult for her to tell me what she wants, but she does makes choices, she makes those choices known in different manners of communicating.

Although participants identified a wide continuum of the quality and quantity of community participation they envisioned for their children, a universal component was the acceptance of their child as a person. In addition, parents had comprehensive visions of the future for their son or daughter encompassing three tangible areas of their child's life: future living, employment, and free-time options. The results from these four areas are discussed in the following sections.

\section{Acceptance}

Parents were fervent about their desire for the acceptance of their sons and daughters by family members, professionals, and the community:

The acceptance of the person with disability, he is accepted as he is, as the human being he is and not looking at the fact that he has such and such condition.... And the respect that there is from the others around him for him and also the love and the desire to help him to make his future more brilliant, prettier, where he feels he is part of a community, part of the others.

The vision of acceptance for their sons and daughters was often embedded within discussions of participants' perceived lack of acceptance of their child and them- 
selves by others. One parent concisely described her challenge:

I just wanted to say something we face here. We have three strikes against us. One, that I'm a fe male; two, that I'm Spanish; and three that I have a son with special needs. Those are the three things that I face every single day.

It seemed that participants had a lack of respect and acceptance from many different people:

There is not only rejection from professionals, also from the friends, from the families. One [such situation] we are going through ... we have the problem, we are living it in our own flesh, we see it when friends reject us for having a child like that.... They turn their backs on us, the family, the same. In other words, not only from professionals, there is [rejection] also from friends and families.

This lack of their child's acceptance by others was clearly expressed as a source of distress in all parent focus groups:

Parent 1: The adults don't teach for their children to learn [acceptance].

Parent 2: But a lot of times, it is that they don't want to hurt you, do you understand?

Parent 3: When it happens once, okay, you let that pass but when it happens 3,005 time more or less. Because there is, you notices [sic] that there is rejection, you notice it, you understand. When there is no longer visits and then they come to my house, they can play with my son's toys as she said. But then, when one goes to their houses for birthday parties, here you don't enter, and they close the door and put him in a room. Isn't that rejection?

\section{Future Living}

Future living was the focus of considerable discussion among parent participants. At the heart of this discussion was the future physical and emotional well-being of their child. Statements made by parents regarding future living options fell into two subcategories: (a) residential and (b) improved skill proficiency.

\section{Residential}

Parents diverged in their thoughts about. the most appropriate future residence for their son or daughter. Some indicated that they anticipated their son or daughter would live in the family home. Others envisioned their child living either in a supervised, residential care facility, or living independently in his or her own apartment or home.

For the many parents who envisioned their child living in the family home where the child would he cared for by family members, primarily the mother, their comments implied that living at home was a natural course of life. It was clear that many of these parents were concerned about what would happen to their son or daughter when the parents could no longer care for their child, "We do not know what is going to happen in the future. We wish we will he there to help them, but we know that the reality is not that." A central part of their vision was finding someone who, in the future, would provide a nurturing environment for their child. Several parents voiced the desire to find a future care giver who would care for their child in ways comparable to their own, "What I would like right now that I am alive is to look for someone ... who could take care of him as I would take care of him."

Many parents believed that finding someone to serve in a parental capacity to ensure their child's needs were met was an essential part of their vision. One parent illustrated this point by sharing a conversation she recently had with her daughter:

When walking back home, I was asking questions to my daughter and in talking with her, she said that when I am no longer here ... she is going to be in charge of supervision of everyone who works with her brother. That she is going to be around there to see that everything is been done right. I told her, "You don't have to take the responsibility of bathing him, of changing his Pampers, of doing the things that I do directly, but I do need somebody to be there to take my place."

The few parents who envisioned their son or daughter living in a supervised residential setting away from the family home thought an important consideration was the physical well being of their child, "where they take care of him." They wanted to feel confident about their child's safety in a future residence.

I picture my son living with me, but at the same time, I picture him more independent. There's a lot of things that he does that are very dangerous, so I'm constantly afraid.... The best it would be as he gets older, I would like him to live in a group home, on weekends he's home. And I like that he can have his own space, I can have my own space, because I'm going to get older. He can live independent, learn, but at the same time I feel safe, he's not alone.

Finally, many parents expressed the desire for. their adult children to live independently in their own homes or apartments, "For my daughter, I dream that she will be able to move away and move to her own apartment ... the future I want for her is to be independent ... with a roommate, not in a group home." For several of these parents, their vision of independent living re flected the preference of their child: 
He is already asking me to become independent. He tells me that he wants me to pick for him an apartment that is upstairs where I live and that I help him in the mornings but then I will have to go home and leave him alone.

\section{Improved Skill Proficiency}

Regardless of their choice of fiture residence for their child, parents expressed the desire for their son or daughter to improve proficiency in activities of daily living skills including communication. Parental hopes for the future included improved ability in activities of daily life that would allow their child to become less dependent on others. These skills included eating, dressing, and personal hygiene-skills that would enable them to "manage by themselves."

My golden dream is that my children would be able to manage by themselves in life ... To be independent is like my daughter who will be already 15 years old ... I have to brush her, I have to wash her clothes yet, I have to tell her how she is when she is in the month. For me it is that if she learns to do all this, she is independent as a person.

Several parents of young adults with significant multiple disabilities emphasized their desire for their son or daughter to have improved communication skills. Representative comments included: "I would like them to respond to me, to talk to me ... one talks to me very little, but the other does not." and "I wish he could communicate a little bit better. [To tell me] 'do you want the light off, the TV on?' You know, I really do wish he could do something like that."

\section{Employment}

Employment was another major element that emerged in parents' discussion of their child's future. The majority of these respondents were parents who also envisioned their child living in their own apartment or home. Parents did not often articulate a specific occupation; however, it was evident that they considered it important that the job be consistent with their child's preferences, "So, start preparing him for a vocation so that he can work, have a work on what he likes not on what my preference is, but something he likes."

All comments regarding employment options indicated parents wanted their children to have meaningful jobs. Comments seemed to reflect participants' emphasis of respect and dignity for their sons and daughters. For most, this meant competitive employment in a job that was not specifically created for a person with a disability, rather than "simulated work for token wages." One parent characterized this as "working in the real world" as opposed to the "artificial thing."

I'd like to see D. be trained for a job skill, a meaningful job skill, such as in a pet shop, in a fire station, or at Marriott Hotel, and I don't mean just cleaning at the Marriott. I mean carrying luggage, being responsible for things as such and taking flowers up, or room service, things like that ... [like our family said] they don't want to see him in a sheltered workshop ... collecting cans to make a living ... or see him with a blue bucket at the corner selling newspapers.

One parent's vision for her son's future included work at a segregated sheltered workshop. For this parent, whose son was working in a sheltered workshop at the time of the focus group, the intent of work was her son's self-esteem and meaningful use of his time.

There are kids that went to school with my son that are just home doing nothing, watching TV, and I am so much more comfortable knowing that my son gets up, goes to work from 8:00-5:00. He's working, and he feels better about himself. He's working on the beltline, but you know, he's wearing a belt, one of the belts that he helped to make.... He's proud, you know, he's proud to show a belt that he helped to make.

The majority of parents who envisioned their child living at home or in a supervised residential setting did not mention employment as a part of their vision of the future. One parent explicitly stated that she did not see employment as a consideration for her son's future.

\section{Leisure Activities}

Across all groups, there were parents who emphasized the importance of leisure activities during their child's free time. Some parents emphasized the importance of their children having leisure time activities of their own choosing, "And her time off, do whatever she wants to do." They also spoke of doing things that their child particularly enjoyed or was "good" at doing.

Many parents wanted their children to be involved in activities in the community. For one parent, a simple outing in the community, made difficult by the physical support needs of her child, was her vision, "I think just leisure time for J. Just to be able to take him like to the show, out somewhere ... in the community, just to go out but it's so hard with his chair, it really is."

Many parents, however, saw their son or daughter in community activities similar to those enjoyed by typical same-age peers. Frequently, these visions of community leisure-time activities involved having friends with whom to do the activities:

I'd like to see my daughter participate in more community activities like she's doing right now. Like participate in church activities. What I want her more, like to have more friends of her age maybe, or older friend like to go and take her with them. That's what I want. Like if they want to go to 
the swimming pool, cone invite her and take her with them.... not with me all the time, because I take her everywhere, you know, to the activities, but I want her to have friends, also.

One parent specifically identified friends without disabilities as an important part of her son's future:

He has a lot of friends at church that are not disabled. He has a couple of friends on the block that are not disabled, and they do come and play with him, give him attention, take him down the street, ride bikes, they go swim, things like that. Those are the kinds of things that interest him and make him happy, and those are the kinds of things that we keep encouraging and want to see more of.

No comments were made related to friendships with other individuals with disabilities.

\section{Discussion}

This study provides important information about Hispanic parents' hopes and expectations of the future for their children with disabilities. The findings consistently reveal that these participants have a diversity of future goals for their sons and daughters. This section includes a discussion of the findings in light of relevant literature with recommendations for practice and directions for future research.

\section{Acceptance}

A recurrent element of acceptance and respect was present in all focus groups. Indeed, parents were most passionate about issues related to acceptance of their child. Parents' concern about rejection or lack of acceptance of their child, and subsequently themselves, that they perceived from others, was expressed as a source of distress. This finding parallels research that indicates that numerous sources of stress for families of children with disabilities originate from the reactions of others outside the family (Singer et. al., 1993).

Parents' sense of isolation from the extended family, neighborhood, and larger community is a recurring theme found in much of the writing by parents of children with disabilities (Taylor et al., 1989). In this study, few parents indicated having a "sense of community." Davidson and Cotter (1991) suggest that the concept of "sense of community" (p. 246) refers to a strong bond between a person and the community in which that person functions, such as a neighborhood. McMillan and Chavis (1986) suggest that the construct of "sense of community" consists of four elements: (a) feelings of belonging or membership, (b) influence, (c) fulfillment of needs, and (d) shared emotional connection. Davidson and Cotter (1991) identify the crucial nature of having a sense of community:
Indeed, the qualities inherent in a sense of community are sometimes considered so vital to human functioning that their absence is believed to produce feelings of isolation, alienation, loneliness, and depression (Sarason, 1974), to stifle growth toward self-actualization (Maslow, 1954); and to frustrate such basic human needs as affiliation (Murray, 1938) and social interest (Adler, 1964). Sarason writes, "The absence or dilution of the psychological sense of community is the most destructive dynamic in the lives of people in our society." (p. 247)

This issue may be particularly relevant for these parent focus group participants. A cultural value most widely recognized in the literature to be associated with the Hispanic population is familism. Familism refers to family unity and interdependence (Hidalgo, 1992). Many participants' extended family members are in their country of origin. The "sense of community" that they may have typically received through their extended families, therefore, was absent. Their responses indicated that this void was not being filled by the neighborhood or school communities. Furthermore, many participants who were geographically close to other family members indicated a lack of adequate support from those family members. This is a particularly noteworthy finding given that familism is possibly the most strongly connected value to the Hispanic population, regardless of national origin (Bailey et al., 1999; Harry, 1992). The value of sharing and cooperation is key to this type of family system from which a member receives emotional security, a sense of belonging, and support throughout the lifespan (Becerra, 1988). Empirical evidence suggests that the social support provided by Hispanic family networks offers powerful protective effects on health and emotional well-being (Vega, 1995). Hispanic families who do not have this type of social support available may be at particular risk. Davidson and Cotter (1991) suggest that sense of community coupled with feelings of efficacy may be motivating and empowering. If a goal is to empower families, this finding indicates the need to understand better how to provide families with a sense of commu nity and also the influence of sense of community has on empowerment.

\section{Future Living}

Issues related to future living generated much discussion by parent participants. Although residential options was a common topic, parents also emphasized improved skill proficiency as part of their vision related to future living.

\section{Residential Options}

Parents expressed diverse expectations in regard to future residential options. Many parents envisioned 
their son or daughter living outside the family home, particularly independently in the young adult's own home or apartment. This finding is reflective of one of the dominant U.S. culture's implicit expectations for individuals exiting high schools (Chadsey-Rusch et al., 1991). Independent living, generally defined as living on one's own or with a spouse or roommate, is one of several goals used in post-school assessments as a desirable outcome and reflects the values of schools, programs, and government agencies (Blackorby \& Wagner, 1996; Kalyanpur \& Harry, 1999).

The few parents who envisioned their child living in a supervised residential setting, such as a group home, expressed concern for their child's safety. That is, the residential option seemed to reconcile these parents concern for their child's safety with their desire for independence for their child. This issue of "letting go" and the risks involved in their child having greater independence resonated throughout the focus groups.

The desire to provide their young adult son or daughter with opportunities for independence while faced with the realities of an unsafe world has been expressed by families in other research studies (e.g., Hanley-Maxwell et al., 1995). For example, Thorin et al. (1996) investigated the "dilemmas" confronting families during the transition of their son or daughter with disabilities to adulthood. A dilemma was defined as occurring when families faced choices between options that presented different, but equally problematic, outcomes. Scoring prominently higher than others was the dilemma between the vision of providing for their child's independence and their desire for their child's health and safety. This dilemma presents parents with a "Catch-22," being torn between giving their child independence, while wanting a separate life for themselves, and knowing the reality of an unsafe world at large.

Many parents, however, envisioned a future in which their child remained with them in the family home. These parents' responses parallel earlier research indicating that Hispanic families were more likely to support a family member with a disability in the family home than were non-Hispanics (Heller et al., 1994). The expectation that their adult-aged son or daughter with disabilities will remain in the family home, however, has also been expressed by non-Hispanic families in other research studies (Epps \& Myers, 1989; Gallivan-Fenlon, 1994; McNair \& Rusch, 1991). One explanation for this expectation may be that parents lack information about available residential options in their communities. For example, parents often lack information and knowledge about the adult service system in general (Brotherson et al., 1993). This issue is even more striking for Hispanic families, given that parents from culturally and linguistically diverse backgrounds are typically less informed than those of the majority culture (Harry, 1992). Nevertheless, despite clear, accurate information about all available options for their child, the visions of many of these families may remain the same. That is, as a result of cultural heritage or personal preference, the quality of life they envision for their child may not include independent living; in essence, their preferred quality of life may not be congruent with how the concept is defined by dominant U.S. cultural values (Kalyanpur \& Harry, 1999). This may be an equally cogent explanation for these participants, because their expectation seemed to be the result of an affirmed, natural progression of life. In family structures, the dominant framework is interdependence with an individual identified with and contributing to the larger group identity of the nuclear and extended family (Gutierrez, 1995). In families for whom extended family living is normative for typical family members, the goal of independent living may be viewed as anathema (Harry et al., 1995).

Harry (1997) identified independent living as one of the cornerstones of American philosophy, noting the normative expectation reflected in the dominant American culture is that youth will make the transition from family life to young adulthood between the ages of 18 and 21 . Harry also points out that for many families from culturally and linguistically diverse backgrounds, the normative expectation may be that marriage is the marker of transition to adulthood. Moreover, in some families, it may be normal for the young person to remain in the family home, even after marriage.

It is interesting to note that, although independent supported living in the community is considered "best practice" as a transition outcome, the majority of individuals with moderate to severe disabilities, including Euro-Americans, live with their families in the family home. For example, a minority, 30\%, of individuals with cognitive disabilities receive residential supports outside the family home (Jaskulski et al., 1995). Frank and Sitlington (1993) interviewed 323 students with disabilities 3 years after graduating from high school and found that most were still living at home.

Studies have indicated that residential issues are of great concern for families of adolescents and young adults with disabilities. Brotherson et al. (1988) interviewed 48 parents of children with cognitive disabilities and physical disabilities concerning their needs in planning for their son's or daughter's future. The need for residential options was most frequently identified by both groups of parents. Thorin and Irvin (1992) found that concerns about residential placements were unequivocally the most stressful ones for parents and siblings of young adults with developmental disabilities. These concerns included the quality and availability of residential options as well as concerns about interactions with residential service providers. In an article recommending future directions and priorities for the National Institute on Disability and Rehabilitation Re- 
search (Lakin, 1996), the authors note that most research, social policy, and resources supporting commu nity access for persons with mental retardation focus on individuals residing outside of the family home. Thus, there is limited research available to indicate the types of approaches necessary to support adults with disabilities and their families when they opt for the young adult to live in the family home.

As an extension of assuming ongoing responsibility for their child in the home, many participants (especially mothers) stressed the importance of finding a caregiver who would provide a nurturing environment for their son or daughter when they could no longer do so. A few parents indicated that this role might be as sumed by siblings. Others suggested that the person did not have to be a relative. However, a common concern of these parents was that the future caregiver must be a person they trust to provide care with the same dignity and respect for their child as they themselves provided. This issue reflects a dilemma faced by many parents of individuals who are likely to need lifelong assistance. Indeed, Apolloni (1989) noted that a prominent service need currently unaddressed in the United States is the "need for ensuring that persons with severe disabilities will have someone they can depend upon to guard and personally advocate their best interest once their parents can no longer serve in this capacity" (p. 284). These issues may be exacerbated by the fact that the extended families of many of these participants remained in their country of origin.

This finding is congruent with family support efforts in the disability field referred to as "permanency planning" (Lakin, 1996; Taylor et al., 1989). For children and youth with disabilities, permanency planning reflects the perspective that a child has the right to a nurturing home and a family. Services and supports that reflect this perspective focus on individual and family supports necessary to maintain the child in the family home (Braddock et al.,1998). For parents whose adult family members remain in the family home, permanency planning may take on a different meaning, focusing on the future when the parents can no longer provide the support their children need (Lakin, 1996). The issue of personal care (e.g., residential) is one of many challenging factors facing these families in permanency planning.

\section{Improved Skill Proficiency}

Although parents' responses indicated a diversity of expectations for their child's future residence, there was consensus among parents on the importance of their child improving proficiency in such skills as activities of daily living.

For some parents, improved skill proficiency was viewed as key to successful independent life in the community. For others, improved ability in activities of daily life was seen as reducing the child's dependence and, hence, parental/caregiver responsibility. The challenges presented by caregiving responsibilities were evident throughout focus group discourse. Parents' vision for their child's improved proficiency in activities of daily living supports efforts by professionals who have advocated for the inclusion of functional skills in the curricula of students with disabilities (Orelove \& Sobsey, 1996; Sitlington et al., 2000). Indeed, individuals may be excluded from some community opportunities as a result of a lack of ability in daily hygiene and other areas of self-care (Farlow \& Snell, 2000).

Several parents' vision included their child's improved communication skills. Their focus was to have the child have the ability to let them know things as simple as what they wanted (e.g., turn on the television, turn off the lights, respond to me). This communication void seemed to evoke an emotional need for parents to have a closer "connection" with their son or daughter. Although all of these parents' children were receiving school services, none of them mentioned that augmentative or alternative communication devices had been used as communication support with their child. This raises the issue of the use of and access to augmentative communication support for students with severe dis abilities.

One study, which focused on current augmentative service delivery and practices, clearly documents this point. The results of this study indicated that children and youth with cognitive impairments or multiple dis abilities are the very individuals who would most benefit from augmentative communication supports: however, they were much less likely to receive these services than children and youth who have cerebral palsy and normal intelligence (For Consumers, 1990). Indeed, results showed the needs of less than $10 \%$ of children and youth who could benefit from alternative/augmentative services were being successfully addressed.

This finding may reflect the widely accepted practice of requiring certain cognitive prerequisites in decisions on who receives augmentative communication support; that is, specific cognitive behaviors must be in place to warrant augmentative communication support (Reichle, 1991; Romski \& Sevcik, 2000). Surveys conducted by Wehmeyer (1998, 1999) strongly document extreme under-use of assistive technology by students and adults with cognitive disabilities. These studies document the appropriateness of assistive technology for individuals, regardless of the severity of their cognitive disabilities, and recognize that all individuals can expand their independence, inclusion, and productivity (including their ability to communicate) through the appropriate use of technology.

Harry et al. (1995) issued a caveat regarding the use of alternative or augmentative communication systems for individuals from diverse cultural backgrounds, emphasizing the importance of parents' preferences regarding 
the use of this type of assistive technology. Furthermore, Smith-Lewis (as cited in Harry et al., 1995) reported that Hispanic parents of children with severe disabilities were resistant to the use of augmentative communication devices, which they perceived to be unnatural or even stigmatizing. Qualitative study of the perspectives of families regarding alternative or augmentative communication indicated that families from diverse ethnic backgrounds wanted professionals to demonstrate greater sensitivity to indigenous communication symbols and to recognize the importance of supporting siblings and the extended family in using the communication systems (Parette et al., 2000). The important point here, however, is to be aware of the parents' preference. Despite Smith-Lewis's findings, the parents in this study clearly yearned for improved ways to communicate with their child and, perhaps, would welcome augmentative communication support for their child.

\section{Employment}

Parents' visions concerning employment for their son or daughter seemed to mirror their residential visions. Typically, parents who envisioned their son or daughter living outside the home also envisioned employment as part of their child's future. Parents often spoke of how important it was that their son or daughter be in an occupation consistent with the child's preferences. Most of these parents wanted their child's job to be competitive community employment. Their visions reflect one of the adult outcomes most explicitly valued by the dominant U.S. culture (Lakin, 1996).

One parent envisioned her son working in a sheltered workshop. This parent seemed to view sheltered work as meaningful work rather than as menial tasks or simulated work for token wages. Some studies have shown that many parents want sheltered employment for their adult children (Hill et al., 1985).

Although this employment option is considered taboo in literature concerning "best practice" for individuals with disabilities, it is important to reflect on the issue of personal and family preference. For example, in interviews on future planning with 48 parents of young adults with disabilities, Brotherson et al. (1988) found that all parents of young adults employed in sheltered workshops considered this a stable and permanent arrangement. Edgerton (1990) further explored this issue in a discussion of the movement toward supported work when implemented without consideration of the preferences of the individuals with disabilities themselves:

In the growing enthusiasm for programs of supported work, many clients have been more or less forced to leave sheltered workshops to accept work placements in the competitive economy. Because many of these people have left all of their friends behind at their workshops and have not made friends at their new workplaces, it is commonplace for them to express great unhappiness about their new and improved lives (p. 152).

Finally, for some parents, employment for their son or daughter did not seem to be part of their vision. Typically, these parents envisioned their child remaining in the family home. Similar to independent living options, one explanation may be that parents were not aware of employment options or perhaps even that employment of any kind was an option. Again, this underscores the importance of providing information to parents concerning employment.

Many of the parents who participated in this study were unemployed, which may help explain some parents' lack of interest in their child's employment. For example, if parents are themselves unemployed and are perhaps having difficulty finding employment (as one participant noted), then the employment of their child who has a disability may have been inconsequential.

Cultural values may be another factor influencing parents whose vision did not seem to include employment (Harry et al., 1999). Although community employment, as with residential options, has been a primary focus in the disability field, it is important to recognize that the meaning of work is culturally based (Harry et al., 1995). Harry (1997) identified economic productivity as one of the cornerstones of U.S. social philosophy by which the value of an individual, including those with disabilities, is determined. This is clearly exemplified in a study that examined the lives of 323 individuals with disabilities 3 years after high school graduation (Frank \& Sitlington, 1993). In this study, full-time (over $37 \mathrm{hr}$ per week) community employment with earnings of $\$ 3.35$ per hour or more was one of the standards by which successful adult adjustment was measured. Harry noted, however, that other cultures do not use economic productivity as an indicator of a person's human worth. Her point is not that economic productivity for persons with disabilities is not good, but rather that, for some families from different cultures, employment for an individual with disabilities is neither expected nor encouraged. For these families, monetary productivity is not a determining factor of a person's value.

\section{Leisure Activities}

The third component of many parents' outlook on the "best life" for their child was filling their child's free time with leisure activities. Citing a wide continuum of quality and quantity, their comments made it clear that participating in community activities was an important element of their child's future, regardless of their residential or employment visions for their child.

The importance of participation in community leisure, recreational, and social activities for individuals 
with disabilities has been clearly recognized in the dis ability field (e.g., Sitlington et al., 2000; Sowers et al., 1996). Leisure and recreation, such as the preferential use of free time and personal relationships/social networks, have been identified as important elements in enhancing quality of life for adults (Halpern, 1993) and are major issues for parents in planning for the future (Turnbull et al., 1989). This is highlighted by the fact that individuals with disabilities typically have more free time than those without disabilities (Moon, 1994).

Many parents wanted leisure activity opportunities that their son or daughter preferred. They specifically wanted activities that their child enjoyed and involved skills that were areas of strength for their child. This finding is consistent with the literature, which places emphasis on personal freedom of choice as a critical element of leisure participation (Dattilo \& Schleien, 1994).

Frequently, parents specifically identified leisure activities in the community that were typically enjoyed by same-age peers. In addition, some parents' visions included friends with whom their young adult child could enjoy these activities.

The finding that parents believe friendships are important to the quality of their child's life is not new (Turnbull et al., 1999). The desire for their child to have friends has been expressed by families in other research studies (e.g., Sowers, 1994). In a survey asking parents which information topics they would find most beneficial to family life, the highest ranked was learning how to help their children develop friendships (Ruef, 1995). Similarly, another survey investigated the preferences of parents of students with moderate and severe/profound disabilities on the amount of time that should be spent during the school day on skill instruction and friendship/social relationship development. Parents of both groups wanted teachers to spend approximately one-fourth of the school week on friendship/social relationship development (Hamre-Nietupski, 1993).

It is important to note that some parents did not discuss social relationships, and a few did not mention leisure activities. This may be attributable to several reasons. First, challenges mentioned by parents throughout focus group discussions may have created harriers to leisure and social activities. These included financial problems and negative attitudes related to dis ability and to ethnic prejudice encountered in the community resulting in withdrawal and isolation from the community. Second, some parents may not have been aware of available leisure opportunities in the commu nity because of lack of information. A third contributing factor may be the emphasis on skill acquisition, to the exclusion of social relationship development, in education as the fundamental outcome of the developmental process (Staub el al.. 2000). A final explanation may be related to cultural factors. Turnbull et al.,
(1999) identified the influence of family within the His panic culture on the interpretation of social relationships. Specifically, their study indicated that socialization within the extended family network of some His panic families might be a valuable contributor to the quantity and quality of their child's friendships. Therefore, companionship and friendships afforded by the child's extended family may have been a reason why friendship outside the family was not a priority for some parent focus group participants.

\section{Summary}

The results of this study consistently revealed that Hispanic parents have a diversity of hopes and expectations concerning future living, employment, and freetime options for their children with disabilities. Their responses indicate the influence of not only the His panic culture, but the multicultural contexts in which these parents live. To provide effective support services to individuals from culturally diverse backgrounds and their families, research must continue to provide a clearer understanding of the perspectives of Hispanic parents concerning their experiences during transition and their preferences for culturally responsive support.

\section{References}

Anderson, P. P. (1989). Issues in serving culturally diverse families of young children with disabilities. Early Child Development and Care, 50,167-188.

Apolloni, T. (1989). Guardianship, trusts, and protective services. In G. H. S. Singer \& L. K. Irvin (Eds.), Support for caregiving families: Enabling positive adaptation to disability (pp. 283-296). Baltimore: Paul H. Brookes.

Bailey, D. B., Skinner, D., Correa, V., Arcia, E., Reyes-Blanes, M. E., Rodriguez, P., et al. (1999). Needs and supports reported by Latino families of young children with developmental disabilities. American Journal on Mental Retardation, 104(5), 437-451.

Banks, J. A. (1994). Transforming the mainstream curriculum. Educational Leadership, 51(8), 4-8.

Becerra, R. M. (1988). The Mexican American family. In C. H. Mindel, R. W. Haberstein, \& R. Wright (Eds.), Ethnic families in America: Patterns \& variations. New York: Elsevier.

Blackorby, J., \& Wagner, M. (1996). Longitudinal post-school outcomes of youth with disabilities: Findings from the National Longitudinal Transition Study. Exceptional Children, 62(5), 399-413.

Braddock, D., Hemp, R., Parrish, S., Westrich, J., \& Park, H. (1998). The state of the states in developmental disabilities: Summary of the study. In D. Braddock, R. Hemp, S. Parish, J. Westrich, \& H. Park (Eds.), The state of the states in developmental disabilities, 5th ed. (pp. 2353). Washington, DC: American Association on Mental Retardation.

Brotherson, M. J., Berdine, W. 1-I., \& Sartini, V. (1993). Transition to adult services: Support for ongoing parent prticipation. Remedial and Special Education, 14(4), 44-51.

Brotherson, M. J., \& Spillers, C. S. (1989). A qualitative study on families with disability at two periods of transition in the- life cycle. Unpublished manuscript, University of Kentucky.

Brotherson, M. J., Turnbull, A. P., Bronicki, G. J., Houghton, J., RoederCordon, C., Summers, J. A., et al. (1988). Transition into adulthood: Parental planning for sons and daughters with disabilities. Education and Training in Mental Retardation, 23(3), 165-174. 
Browning, P. L., Dunn, C., Rabren, K., \& Whetstone, M. (1995). Post-school outcomes for students with disabilities: A U.S. synopsis. Issues in Special Education and Rehabilitation, 10(1), 31-37.

Carr, S. C., \& Ratcliff, E. (1994). Partners For transition: Preparing students for the future. Paper prepared for the Annual National Conference of the American Council on Rural Special Education, Austin, TX.

Chadsey-Rusch, J., Rusch. F. R., \& O'Reilly, M. G. (1991). Transition from school to integrated communities. Remedial and Special Education, 12(6), 23-33.

Chadsey-Rusch, J., \& Heal, L. (1995). Building consensus from transition experts on social integration and outcomes. Exceptional Children, 62, 165-186.

Cimera, R. E., \& Rusch, F. R. (2000). Transition and youth with mental retardation: Past, present, and future. In M. L. Wehmeyer \& J. R. Patton (Eds.), Mental retardation in the 21st century (pp. 59-70), Austin, TX: Pro-Ed.

Crago, M. B., \& Eriks-Brophy, A. A. (1993). Feeling right: Approaches to a family's culture. Volta Review, 95(5), 123-129.

Creswell, J. (1994). Research design: Qualitative and quantitative approaches. Thousand Oaks, CA: Sage.

Dattilo, J., \& Schleien, S. J. (1994). Understanding leisure services for individuals with mental retardation. Mental Retardation, 32(1), 53-59.

Davidson, W. B., \& Cotter, P. R. (1991). The relationship between sense of community and subjective well-being: A first look. Journal of Community Psychology, 19, 246-253.

Dennis, R. E., Williams, W., Giangreco, M. F., \& Cloninger, C. J. (1993). Quality of life as context for planning and evaluation of services for people with disabilities. Exceptional Children, 59(6), 499-512.

DeStefano, L., \& Wermuth, T. R. (1992). IDEA (P.L. 101-476: Defining a second generation of transition services. In F. R. Rusch, L. DeStefano, J. Chadsey-Rusch, L. A. Phelps, \& E. Szymanski (Eds.), Transition from school to adult life: Models, linkages, and policy (pp. 5-15). Sycamore, IL: Sycamore.

Edgerton, R. B. (1990). Quality of life from a longitudinal research perspective. In R. L. Schalock (Ed.), Quality of life: Perspectives and issues (pp. 193-210). Washington, DC: American Association on Mental Retardation.

Epps, S., \& Myers, C. L. (1989). Priority domains for instruction, satisfaction with school teaching, and post-school living and employment: An analysis of perceptions of parents of students with severe and profound disabilities. Education and Training in Mental Retardation, 24(2), 157-1.67.

Everson, J. M., \& Moon, M. S. (1987). Transition services for young adults with severe disabilities: Defining professional and parental roles and responsibilities. Journal of Association for Persons with Severe Handicaps, 12(2), 87-95.

Farlow, L. J., \& Snell, M. E. (2000). Teaching basic self-care skills. In M. E. Snell \& F. Brown (Eds.), Instruction of students with severe disabilities (5th ed.) (pp. 331-380). Columbus, OH: Merrill.
For consumers: Populations and practices in Alternative/Augmentative Communication. (1990). Augmentative Communication News, 3(4), 1-4.

Frank, A. R., \& Sitlington, P. L. (1993). Graduates with mental disabilities: The story three years later. Education andTraining in Mental Retardation, 28(1), 30-37.

Freedman, R. I., Krauss, M. W., \& Seltzer, M. M. (1997). Aging parents' residential plans for adult children with mental retardation. Mental Retardation, 35(2), 114-123.

Gallivan-Fenlon, A. (1994). Their senior year: Family and service provider perspectives on the transition from school to adult life for young adults with disabilities. Journal of the Association for Persons with Severe Handicaps, 19(1), 11-23.

Garcia-Preto, N. (1996). Latino families: An overview. In M. McGoldrick, J. Giordano, \& Pearce, J. K. (Eds.), Ethnicity \& family therapy (pp. 141-168). New York: The Guilford Press.

Guha, E. G., \& Lincoln, Y. S. (1989). Fourth generation evaluation. Newbury Park, CA: Sage Publications, Inc.

Gutierrez, L. M. (1995). Empowerment and Latinos: Implications for practice. Family Resource Coalition Report: Empowerment and Latino Families, $13(3$ \& 4), 5-8.

Guzman, B. (2001, May). The Hispanic population. Census 2000 Brief, U.S. Bureau of the Census. www.census.gov/ population/www/socdem/hispanic.html.

Halpern, A. S. (1993). Quality of life as a conceptual framework for evaluating transition outcomes. Exceptional Children, 59(6), 486-498.

Hamre-Nietupski, S. (1993). How much time should be spent on skill instruction and friendship development? Preferences of parents of students with moderate and severe/ profound disabilities. Education and Training in Mental Retardation, 28, 220-231.

Hanley-Maxwell, C., Whitney-Thomas, J., \& Pogoloff, S. M. (1995). The second shock: A qualitative study of parents' perspectives and needs during their child's transition from school to adult life. Journal of the Association for Persons with Severe Handicaps, 20(1), 3-15.

Harry, B. (1992). Cultural diversity, families, and the special education system. New York: Teachers College Press.

Harry, B. (1997). 1996 TASH Annual Conference: Excerpts from opening plenary session remarks. TASH Newsletter, 23(1), 9-11.

Harry, B., Grenot-Scheyer. M., Smith-Lewis, M., Park, H., Xin, F., \& Schwartz, L. (1995). Developing culturally inclusive services for individuals with severe disabilities. Journal of the Association of Persons with Severe Handicaps, 20(2), 99-109.

Harry, B., Rueda, R., \& Kalyanpur, M. (1999). Cultural reciprocity in sociocultural perspective: Adapting the normalization principle for family collaboration. Exceptional Children, 66(1), 123-136. 
Heller, T., Markoardt, R., Rowitz, L., \& Farber. B. (1994). Adaptation of Hispanic families to a member with mental retardation. American Journal on Mental Retardation, 99(3), 289300 .

Heller, T., Miller, A. B., \& Factor, A. (1997). Adults with mental retardation as supports to their parents: Effects on parental caregiving appraisal. Mental Retardation, 35(5), 338-346.

Hidalgo, N. M. (1992). "1 saw Puerto Rico once": A review of the literature on Puerto Rican families and school achievement in the United States (Report No. 12). Baltimore: Johns Hopkins University, Center on Families, Communities, Schools, \& Children's Learning.

Hill, J., Seyforth, J., Banks, P., Wehman, P., \& Orelove, F. (1985). Parent/guardian attitudes toward the working conditions of their mentally retarded children. Exceptional Children, 54(1), 9-24.

Jaskulski, T., Lakin, K. C., \& Zierman, S. A. (1995). The journey to inclusion. Washington, DC: President's Committee on Mental Retardation.

Johnson, J. R., \& Rusch, F. R. (1993). Secondary special education and transition services: Identification and recommendations for future research and demonstration. Career Development for Exceptional Individuals, 16(1), 1-18.

Kalyanpur, M., \& Harry, B. (1999). Culture in special education. Baltimore: Paul H. Brookes.

Knodel, J. (1993). The design and analysis of focus group studies: A practical approach. In D. L. Morgan (Ed.), Successful focus groups: Advancing the stale of the art (pp. 35-50). Newbury Park, CA: Sage.

Krueger, R. A. (1993). Quality control in focus group research. In D. L. Morgan (Ed.), Successful focus groups: Advancing the state of the art (pp. 137-149). Newbury Park, CA: Sage Publications.

Krueger, R. A. (1994). Focus groups: A practical guide for applied research (2nd ed.). Thousand Oaks, CA: Sage.

Lakin, C. (Ed.). (1996). Research on community integration of persons with mental retardation and related conditions: Current knowledge, emerging challenges, and recommended future directions Preliminary report]. Washington, DC: U. S. Department of Education, National Institute on Disability and Rehabilitation Research.

Lynch, E. W., \& Hanson, M. J. (1998). Developing crosscultural competence: A guide for working with children and their families (2nd ed.). Baltimore, MD: Paul H. Brookes $C o$.

Magana, S. M. (2000). Mental retardation research methods in Latino communities. Mental Retardation, 38(4), 303-315.

Marin, G., \& Marin, B. V. (1991). Research with Hispanic populations. Newbury, Park, CA: Sage.

Marshall, C., \& Rossman. G. B. (1995). Designing qualitative research. Thousand Oaks, CA: Sage Publications.

Massey, D. S., Zambrana, R. E., \& Bell, S. A. (1995). Contemporary issues in Latino families: Future directions for research, policy, and practice. In R. E. Zambrana (Ed.), Understanding Latino families: Scholarship, policy, and practice (pp. 190-204). Thousand Oaks, CA: Sage Publications.
McMillan, D. W., \& Chavis, D. M. (1986). Sense of community: A definition and theory. Journal of Community Psychology, 14(1), 6-23.

McNair, J., \& Rusch, F. R. (1991). Parent involvement in transition programs. Mental Retardation, 29(2), 93-101.

Miles, M. B., \& Huberman, A. M. (1994). Qualitative data analysis: A sourcebook of new methods. Newbury Park, CA: Sage.

Moon, S. M. (1994). The case for inclusive school and community recreation. In S. M. Moon (Ed.), Making school and community recreation fun for everyone: Places and ways to integrate. Baltimore, MD: Paul H. Brookes Publishing Co., Inc.

Moon, M. S., \& Inge, K. (2000). Vocational preparation and transition. In M. E. Snell \& F. Brown (Eds.), Instruction of students with severe disabilities (5th ed.). (pp. 591-628). Columbus, OH: Merrill.

Morgan, D. L. (Ed.) (1993). Successful focus groups: Advancing the state of the art. Newbury Park, CA: Sage.

Morgan, D. L., \& Krueger, R. A. (1993). When to use focus groups and why. In D. L. Morgan (Ed.), Successful focus groups: Advancing the state of the art (pp. 3-19). Newbury Park, CA: Sage.

National Center for Education Statistics. (2000). Dropout rates in the United States: 1998. U.S. Department of Education, Office of Educational Research and Improvement (NCES, 2000-022).

National Council on Disability. (November, 2001). Transition and post-school outcomes for youth with disabilities: Closing the gaps in postsecondary education and employment. Washington, DC.: Author.

Navarrete, L. A., \& White, W. J. (1994). School to community transition planning: Factors to consider when working with culturally diverse students and families in rural settings. Rural Special Education Quarterly, 13(1), 51-56.

Orelove, F. P., \& Sobsev, D. (1996). Educating children with multiple disabilities: A transdisciplinarv approach (2nd ed.). Baltimore, MD: Paul H. Brookes Publishing Co.

Ortiz, V. (199.5). The diversity of Latino families. In R. E. Zambrana (Ed.), Understanding Latino families: Scholarship, policy, and practice (pp. 18-39). Thousand Oaks, CA: Sage.

Parette, H. P., Jr., Brotherson, M. J., \& finer, M. B. (2000). Giving families a voice in augmentative and dternative communication decision making. Education and training in mental retardation and developmental disabilities, 35(2), 177-190.

Patton, M. Q. (1990). Qualitative evaluation and research methods. Newbury Park, CA: Sage.

Reichle, J. (1991). Defining the decisions involved in designing and implementing augmentative and alternative communication systems. In J. Reichle, J. York, \& J. Sigafoos (Eds.), Implementing augmentative and alternative communication: Strategies for learners with severe disabilities (pp. 39-60). Baltimore: Paul H. Brookes. 
Romski, M. A., \& Sevcik, R. A. (2000). Communication, assistive technology, and mental retardation. In M. L. Wehmeyer \& J. R. Patton (Eds.), Mental retardation in the 21st century (pp. 299-314). Austin, TX: Pro-Ed.

Ross. J. K. (1996). Social Security: Disability programs lag in promoting return to work. Testimony before the Special Committee on Aging, U.S. Senate. (GAO/T-HEHS-96-147). Washington, DC: United States General Accounting Office.

Ruef, M. (1995). Informational priorities of parents regarding the challenging behaviors of their sons and daughters: Results of a national survey. Unpublished manuscript, Beach Center on Families and Disability, University of Kansas.

Schalock, R. L. (1997). Considering culture in the application of quality of life. In R. L. Schalock \& G. N. Siperstein (Eds.), Quality of life: Vol. 2. Application to persons with disabilities (pp. 225-243). Washington, DC: American Association on Mental Retardation.

Schalock, R. L. (2000). Three decades of quality of life. In M. L. Wehmeyer \& J. R. Patton (Eds.), Mental retardation in the 21 st century (pp. 335-356). Austin, TX: Pro-Ed.

Seidman, I. E. (1991). Interviewing as qualitative research: A guide for researchers in education and the social sciences. New York: Teachers College Press.

Shafer, M. S., \& Quiroga, T. (1993). Perspectives on transition among Hispanic and disabled youth. Journal of Vocational Rehabilitation, 3(1), 54-60.

Singer, G. H. S., Irvin, L. K., Irvine, B., Hawkins, N. E., Hegreness, J., \& Jackson, R. (1993). Helping families adapt positively to disability: Overcoming demoralization through community supports. In G. H. S. Singer \& L. E. Powers (Eds.), Families, disability, and empowerment: Active coping skills and strategies for family interventions (pp. 67-83). Baltimore: Paul H. Brookes.

Sitlington, P. L., Clark, G. M., \& Kolstoe, O. P. (2000). Transition education and services for adolescents with disabilities. Boston: Allyn \& Bacon.

Sowers, J. (1994). The New Hampshire natural supports project-Project report. Concord: University of New Hampshire, Institute on Disability.

Sowers, J., Glang, A. E., Voss, J., \& Cooley, E. (1996). Enhancing friendships and leisure involvement of students with traumatic brain injuries and other disabilities. In L. E. Powers, G. H. S. Singer, \& J. Sowers (Eds.), On the road to autonomy: Promoting self-competence in children and youth with disabilities (pp. 347-371). Baltimore: Paul H. Brookes.

Staub. D., Peck, C. A., Gallucci, C., \& Schwartz, 1. (2000). Peer relationships. In M. L. Wehmeyer \& J. R. Patton (Eds.), Mental retardation in the 21st century (pp. 381-408), Austin, TX: Pro-Ed.

Stewart, D. W., \& Shamdasani, P. N. (1990). Focus groups: Theory and practice. Newbury Park, CA: Sage.

Szapocznik, J., \& Kurtines, W. (1993). Family psychology and cultural diversity: Opportunities for theory, research, and application. American Psychologist, 48, 400-407.

Taylor, S. J., Knoll, J. A., Lehr, S., \& Walker, P. M. (1989). Families for all children: Value-based services for children with disabilities and their families. In G. H. S. Singer \& L. K. Irvin (Eds.), Support for caregiving families: Enabling positive adaptation to disability (pp. 41-53). Baltimore, MD: Paul H. Brookes.

Tesch, R. (1990). Qualitative research: Analysis types and software tools. New York: Falmer Press.
Thorin, E. J., \& Irvin, L. K. (1992). Family stress associated with transition to adulthood of young people with severe disabilities. Journal of the Association, for Persons with Severe Handicaps, 17(1), 31-39.

Thorin, E., Yovanoff, P., \& Irvin, L. K. (1996). Dilemmas faced by families during their young adults' transitions to adulthood: A brief report. Mental Retardation, 34(2), 117t20.

Turnbull, A. P., Pereira, L., \& Blue-Banning, M. (1999). Parents' facilitation of friendships between their children with a disability and friends without a disability. Journal of the Association for Persons with Severe Handicaps, 24(2), 8599.

Turnbull, H. R., \& Turnbull, A. P. (2000). Free appropriate public education: The law and children with disabilities (6th ed.). Denver: Love.

Turnbull, H. R., Turnbull, A. P., Bronicki, G. J., Summers, J.A., \& Roeder-Cordon, C. (1989). Disability and the family: A guide to decisions for adulthood. Baltimore, MD: Paul $\mathrm{H}$. Brookes.

U. S. Census Bureau. (1996). Current population reports. www.census.gov/prod/1/pop/p25-1130.

Vaughn, S., Schumm, J. S., \& Sinagub, J. (1996). Focus group interviews in education and psychology. Thousand Oaks, CA: Sage.

Vega, W. A. (1995). The study of Latino families: A point of departure. In R. E. Zambrana (Ed.), Understanding Latino families: Scholarship, policy, and practice (pp. 3-17). Thousand Oaks, CA: Sage.

Wehman, P., Bricout, J., \& Kregel, J. (2000). Supported employment in 2000: Changing the locus of control from agency to consumer. In M. L. Wehmeyer \& J. R. Patton (Eds.), Mental retardation in the 21st century (pp. 115150). Austin, TX: Pro-Ed.

Wehmeyer, M. L. (1998). National survey of the use of assistive technology by adults with mental retardation. Mental Retardation, 36(1), 44-51.

Wehmeyer, M. L. (1999). Assistive technology and students with mental retardation: Utilization and barriers. Journal of Special Education Technology, 14(1), 48-58.

Ysseldyke, J. E., Algozzine, B., \& Thurlow, M. L. (2000). Critical issues in special education. New York: Houghton Mifflin Company.

Article received: October 16, 2001

Final acceptance: August 21, 2002

Editor in charge: George H. S. Singer

This research was supported by a grant from the National Institute on Disability and Rehabilitation Research to the Beach Center on Disability, Grant \#H133B30070. 